\title{
A COMPENDIOUS REVIEW ON THE METABOLIC SYNDROME; ITS IMPACT ON THE QUALITY OF LIFE
}

\begin{abstract}
RAJALAKSHIMI V ${ }^{1}$, VIJEY AANANDHI M²*
${ }^{1}$ Department of Research Scholar, School of Pharmaceutical Sciences, Vels Institute of Science Technology and Advanced Studies (VISTAS), Chennai, Tamil Nadu, India. ${ }^{2}$ Department of Pharmaceutical Chemistry and Analysis, School of Pharmaceutical Sciences, Vels Institute of Science Technology and Advanced Studies (VISTAS), Chennai, Tamil Nadu, India. Email: hodpchemistry@velsuniv.ac.in
\end{abstract}

Received: 10 October 2018, Revised and Accepted: 11 December 2018

ABSTRACT

Background: Metabolic syndrome (MetS), a comprehensive condition is universally described as a group of several causative factors or abnormalities directly linked with insulin resistance that obviously augment the threat mainly for coronary heart disease, diabetes mellitus Type 2, some types of cancers and sleep disturbances, etc. MetS is a contemporary condition that covers a wide-ranging display of disorders with definite metabolic anomalies demonstrating at different times. Consequently, the threat of MetS remains epidemic. This review will potentially study significant factors such as central adiposity, insulin resistance, hypertension, and dyslipidemia; increased inflammation, environmental factors, and genetic predisposition are involved in MetS development.

Purpose: This review provides the available facts to validate the relationship between MetS and quality of life.

Methods: A thorough exploration in many search engines such as PubMed, Medline, Science direct, EMBASE, and Google scholar was carried out to recognize qualified studies.

Results: Almost all studies suggested that MetS is significantly associated with impair quality of life. Lifestyle intervention holds the early preference and such non-pharmacological therapy combines specific suggestion on diet and physical activity with behavioral strategies. For the individuals, where contributing factors are not sufficiently condensed with lifestyle changes, pharmacological treatment should be considered.

Conclusion: Therefore, the current study reviews the outline of literature interrelated with the MetS's characterization, epidemiological existence, pathological process, and management advance for all the risk factors encompassing metabolic disorder.

Keywords: Cardiovascular disorders, Inflammation, Insulin resistance, Metabolic syndrome, Obesity, Occurrence.

(C) 2018 The Authors. Published by Innovare Academic Sciences Pvt Ltd. This is an open access article under the CC BY license (http://creativecommons. org/licenses/by/4. 0/) DOI: http://dx.doi.org/10.22159/ajpcr.2018.v11s4.31687

\section{INTRODUCTION}

In the recent past years, an authentic torrent of research has been observed regarding a new problem-solving category: The metabolic syndrome (MetS) [1]. It is a chronic provocative outbreak highly contributing mainly to cardiovascular mortality [2]. The definition, conditions, and management choices are now strongly debated. Consequently, the threat of MetS can be truly considered an epidemic $[3,4]$. MetS, rise up the health-care cost, which becomes a significant burden to the developed and developing countries all over the world. MetS instigation is recognized to a degree of inherited tendency formed by several genes united with an inactive routine and a diet including surfeit calories. Detection of patients among characteristics of this condition and suitable management is essential to diminish the undesirable consequences on health linked with MetS [5]. The major intention of this review is to put in forth various facets of MetS of shedding some radiance on the particular condition.

\section{DEFINITIONS AND THE DIAGNOSTIC CRITERIA OF METS}

The MetS encompasses the grouping of interrelated cardiovascular risk factors, together with central obesity, hypertension, dyslipidemia, and also hyperglycemia and is extensively established that it is budding and emerging global issue. It is a chief and intensifying communal health challenge globally due to the urbanization development, excess energy intake, cumulative obesity, and also lethargic lifestyle. Prior identification or prognosis is a key to utilize effectively lifestyle and risk factor adaptation. Since then, the perception of MetS has gradually emerged into medical practice, and quite a few definitions have been projected to portray MetS as considered in more detail later [6,7].

Recently, numerous functioning definitions have been prepared for the MetS. The MetS syndrome is generally categorized by central abdominal obesity, dyslipidemia, amplified blood pressure (BP), glucose intolerance, and insulin resistance [9-12]. In the year 1998, the WHO initiated a definition for the MetS [1], and later it was modified in the year 1999 [9]. By the year 1999, even the European group for the study of insulin resistance organized their definition [10], whereas by 2001, the National Cholesterol Education Program's Adult Treatment Panel III (ATP III) [11], adapted by an American Heart Association, 2005 [3] and also the International Diabetes Federation in 2005 [12].

\section{EPIDEMIOLOGY}

The MetS started as awareness rather than a diagnosis. In 1920, Mets instigated with the association of elevated BP, hyperglycemia, and gout. Then, late in the 1940 's, the abdominal obesity was also commonly linked with the metabolic abnormalities. Later, it was described that the etiology of the MetS remains versatile; regarded as a cluster of risk factors for diabetes and cardiovascular disease (CVD). Many have struggled to progress diagnostic criteria for the identification of the MetS [13-15]. Millions of people all through the world have been diagnosed with MetS [16]. Mostly European countries and in the western nations the commonness of the MetS has reached almost onethird of the total population, and the occurrence is still advanced in the age groups $[17,18]$. The prevalence of the MetS is increasing all over the 
world due to the worldwide increase in central adiposity and inactive lifestyles [19]. Nearly, the MetS has spread its condition on one-fourth population of North Americans [20]. Akin, occurrence in MetS has been observed in Scandinavian populations [21]. According to the NHANES study, the frequency of the MetS in the western countries increased in middle-aged populations. MetS has become further rampant with escalating age paralleled by an increase in age-associated diseases and anomalies [22] Fig. 1.

The incidence of MetS ranges from $<10 \%$ to $84 \%$. Number of factors may be involved in the incidence of MetS, pertaining to the province, metropolitan or rural setting, gender, age, ethnicity, gut microbiota, food patterns, and the culture of the population studied. Furthermore, sex-related variations in MetS predominance all through the world are not constant. These dissimilarities may be due to cultural diversity and diversified waist circumference used in altered populations [23]. Sophisticated socioeconomic status, inactive lifestyle, and an increased BMI (Body Mass Index) were considerably connected to MetS [24]. A study detected that there is a steady elevation found in the incidence of MetS since two decades all through their 60s and 70s [25]. Consequently, this global health issue needs to be addressed; hence, preventive health procedures should be carried out.

The schematic representations of the MetS are as follows Fig. 2:

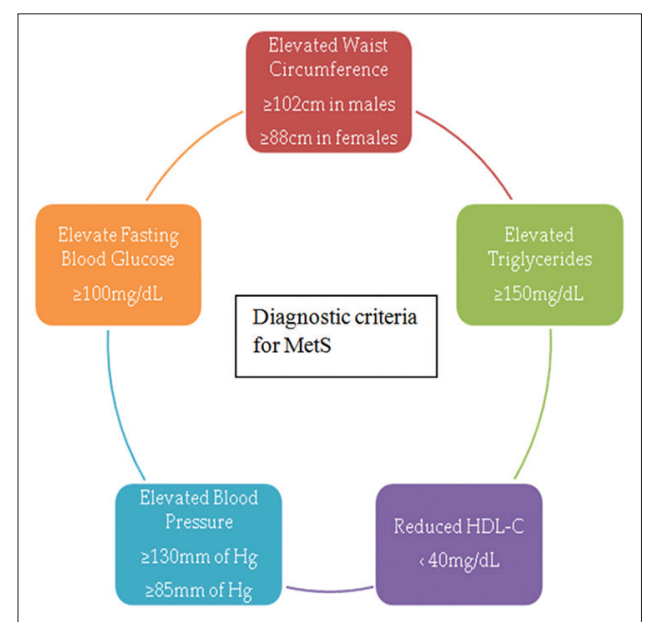

Fig. 1: The diagnostic criteria for metabolic syndrome

\section{ETIOPATHOGENESIS}

The mechanisms involved in the pathogenesis of MetS are so intricate that requires a complete elucidation. Although MetS varies in distribution; recently, it has distributed even in the developing countries which accentuate the significance of environmental and routine life aspects such as the burning up of additional calories along with the deficit of physical activity as being chief contributors [26.]

MetS is characterized by prolonged low-grade inflammatory condition emerging with adipose tissue and, in addition, involves immune cells, as a result, discharges inflammatory substances such as cytokines. Furthermore, it leads to endothelial dysfunction which may cause an increased risk of atherothrombosis, hypertension, and CVD. Although the pathogenesis of the MetS and each of the mechanism is complex, insulin resistance, abdominal adiposity, atherogenic dyslipidemia, hypertension, persistent stress, and chronic inflammation remain the most significant risk factors of the syndrome [27] Fig. 3.

\section{Insulin resistance}

Hyperinsulinemia coupled with insulin resistance seems to be an essential factor involved in the pathogenesis of the MetS. Augmented free fatty acids (FFAs), which are circulating due to insulin resistance-mediated, are thought to enact a key role in the development of MetS. In adipose tissue, inhibition of lipolysis mediated by insulin resistance, thus leading to in rise in circulating FFAs. These further prevent the protein kinase. FFAs hinder protein kinase stimulation in the muscle proceeding with decreased glucose uptake [28].

In the presence of the MetS, insulin has a selective dysfunction so that it does not diminish the hepatic glucose output, but rather increases it, and further causing dyslipidemia [29]. Insulin resistance also causes an increase in serum consistency, augmented conversion of prothrombin to thrombin, and ultimately the discharge of inflammatory substances like cytokines from the fat cell which facilitates amplified risk of CVD [30].

Another factor that contributed to the development of the MetS is an excessive nutrient intake which can alter the mitochondrial function leading to defective insulin secretion and Type II diabetes mellitus [31]. Furthermore, disproportionate nutrient intake can result in obesity, as visceral fat. Insulin resistance is more developed visceral fat deposition rather than subcutaneous deposition which directed to a better supply of FFAs that cause an increased triglyceride synthesis. This altered lipid metabolism which occurred in the liver ends up causing in the rise in low-density lipoprotein cholesterol (LDL-C) and diminished high-density lipoprotein cholesterol (HDL-C) levels [32].

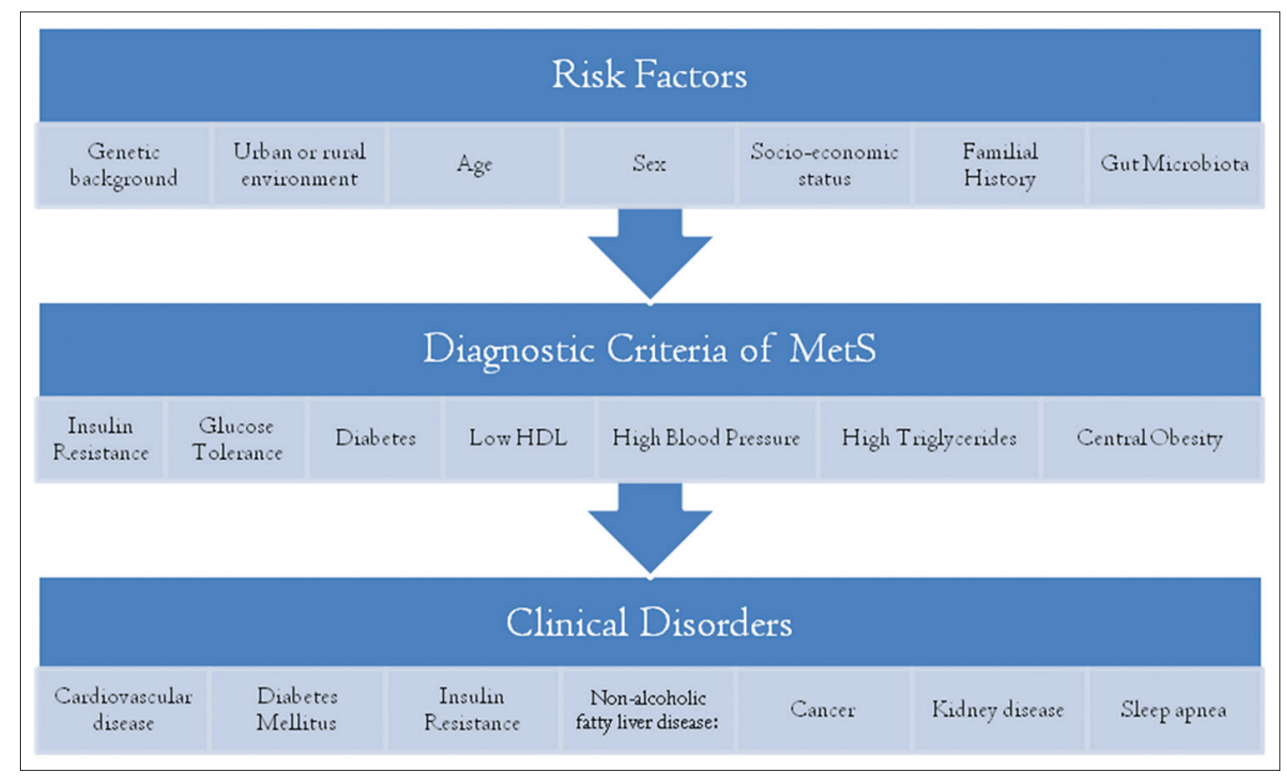

Fig. 2: Schematic representation of metabolic syndrome 
The inherited fat predominantly secretes the inflammatory cytokines tumor necrosis factor- $\alpha$ (TNF- $\alpha$ ) and interleukin 6 (IL6). The production of cytokines causes an increase in lipolysis and results in hypertriglyceridemia [33]. Consequently, this visceral fat will be coupled with metabolic alterations. A genetic susceptibility for both central adiposity and the expansion of the MetS is probably an underlying cause of the development [34].

\section{Abdominal obesity as the driving force}

In many areas of the world, rising incidence of adiposity is the main dynamic force following the high commonness of the MetS. The problem of central obesity is also seen equally in young people, as well as in the elderly. In regard to the metabolic anomalies that cause the risk for cardiovascular and other ailments, waist circumference measurement may prove to be the sole indicator [35]. Although fat deposits regarded, as an unreceptive storage site for energy that may possibly be use in the moment that we need [36].

Adipose tissue along with its related deformities can influence to cause insulin resistance due to alterations in the FFA levels within cells. These effects of insulin resistance can cause interrelated changes leading to oxidation of fatty acid thereby causing an alteration in the endothelial function [37].

Even, an association exists between a prior recognizable history of obesity and MetS development was identified. Numerous studies have shown that genetic background could manipulate MetS origin. The genetic constitution of an individual with leptin polymorphisms was also linked with metabolic abnormalities, thus proved to contain elevated concentration of leptin. Yet, it has been shown that alteration in the growth of microorganisms could progress MetS. Another study reported that MetS risk factor includes the measurement of depression. The crucial reason for the MetS genesis is the environmental factor. Other report exhibited a correlation between MetS and consumption of excessive food. And also, a study [38] reported that the consequence of a high sugar diet causes an augmented oxidative stress which leads to deterioration in the cardiovascular function and eliminate female defense again cardiovascular dysfunction. Furthermore, in elderly obese patients, MetS has been related to abdominal obesity and inflammation at advanced levels, measured by IL-6 (ILs), TNF- $\alpha$, and PAI-1 [39]. Moreover, adiposity is regarded as the type of obesity mainly tied with MetS and determined as the predictable causative factor for the diagnosis of the syndrome [40].

In addition, numerous drugs, such as corticosteroids, antipsychotics, antidepressants, and antihistamines can influence MetS characteristics including adiposity and glucose intolerance [41].

\section{Neurohormonal activation}

Stimulation of the renin-angiotensin system also provides a significant neurohumoral pathway contributing further mechanistic insights into the advancement of metabolic abnormalities. As a consequence of Angiotensin-converting enzyme stimulation, angiotensin-II, as well it is synthesized by adipose tissue [42]. Through activation of the angiotensin receptor (AT-1), proceeds to the generation of reactive oxygen species (ROS) [43] which produces major result proceeding with LDL-oxidation, endothelial dysfunction, aggregation of platelets, and generation of lectin-like oxidized LDL receptor-1 (LOX-1) [44]. Such process initiates inflammation, endothelial injury, and proliferation of cells that contribute to the advancement of BP, high lipid levels, blood sugar, cardiac dystrophy, and CVD [45].

\section{Hypertension}

Numerous metabolic abnormalities as shown in Fig. 4, mainly central adiposity, and increased blood sugar level are the main causes of essential hypertension. Studies suggest that insulin resistance and hyperinsulinemia leads to the stimulation of sympathetic system, and, consequently, the renal system enhance sodium reabsorption, the heart shows increased cardiac output, and also increased arterial pressure causes vasoconstriction ensuing in hypertension. In a study, it was

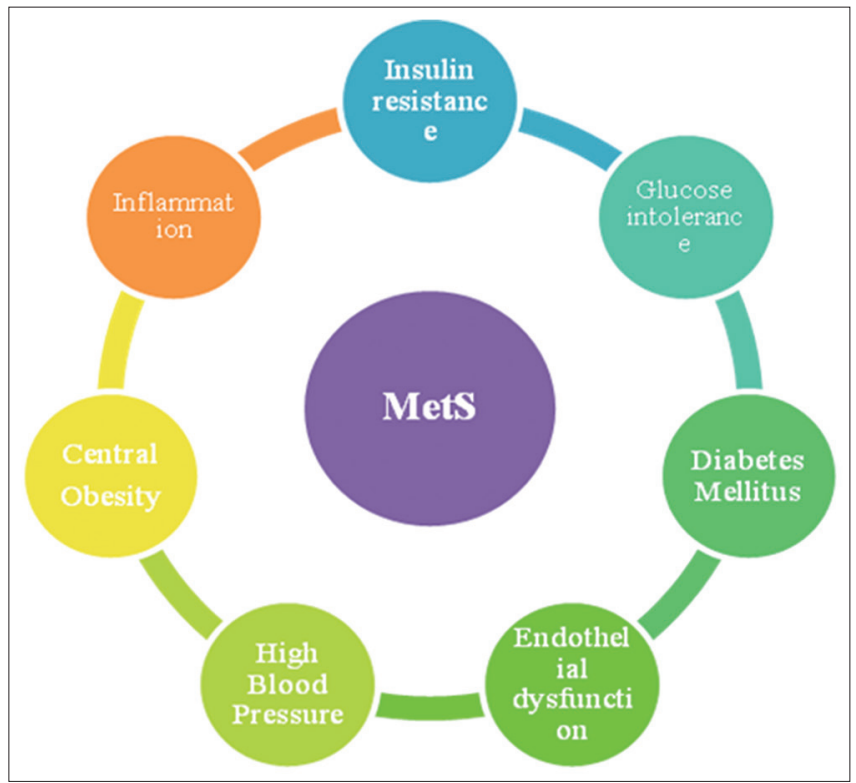

Fig. 3: Risk factors involved in metabolic syndrome

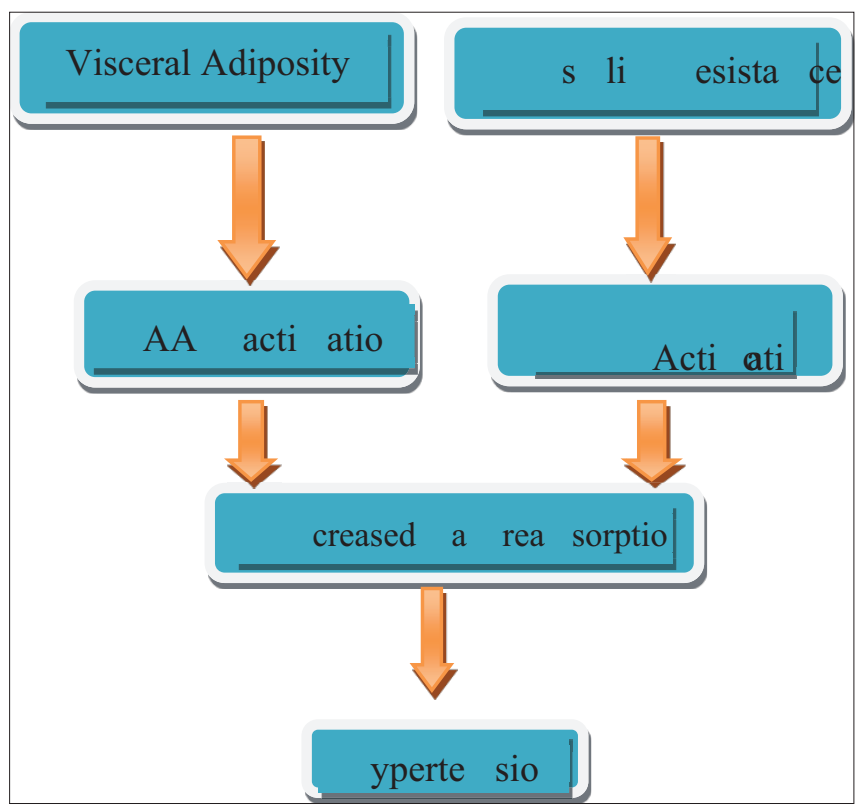

Fig. 4: Pathogenesis of hypertension in the metabolic syndrome. *Renin angiotensin aldosterone system. "Somatic nervous system

shown that the MetS was present in a high proportion of the sample of patients with hypertension $[46,47]$.

\section{Inflammation}

Inflammation plays an important part in the development of cardiovascular disease and proved by the presence of inflammatory markers seen elevated in patients with MetS [48]. Macrophages present inside the fat cells produce TNF- $\alpha$, and its synthesis enhances with an elevation in the weight of adipose tissue. This production of TNF- $\alpha$ leads to the inactivation of tyrosine kinase receptors, the increasing FFA due to lipolysis and inhibition of adiponectin discharge are normally caused by TNF- $\alpha$ stores in the adipose tissue [49]. Therefore, prominent serums levels of TNF- $\alpha$ are related with central adiposity and glucose intolerance, as these are the chief elements of MetS [50].

Adipocytes and immune cells have complex regulatory mechanisms to produce IL-6 [51]. However, synthesis of IL-6 enhances with raise in 
adiposity and insulin resistance. This formed cytokine works on the hepatocytes, bone marrow, and vascular endothelium, thus causing an augmented production of reactive proteins. Quite number of researches has established a relationship amidst elevated $C$ reactive protein levels and the advancement of MetS [53]. IL-6 also enhances fibrin levels ensuing state of coagulation and advances expression of endothelial cells [54].

\section{Dyslipidemia}

It is characterized by a range of lipid level deformities that affect in the composition, metabolism, and inherited activities of lipoproteins that comprises an increase in lipoproteins, increased triglycerides (TG), enhanced LDL-C levels, and suppressed HDL-C levels. Insulin resistance directed to cause irregular levels in cholesterol in several ways. In general insulin usually diminishes breakdown of lipids in adipocytes, ensuing in increased FFA levels. Furthermore, results in augment production of very LDL (VLDL) and thus causes a reduction in VLDL clearance by enhancing an atheroma formation [54]. Thereby, it is understood that the augmented VLDL secretion causes dyslipidemia associated with insulin resistance [55].

\section{Inheritance}

An immense difference in the susceptibility and age, propose a major relation exist between genetic and environmental factors [56]. Elevated plasma glucose to unusual levels is chiefly caused by genetic predisposition to the insulin secretion when shared with insulin resistance. The metabolic alterations are advantageous for those subjects who are poorly nourished all through the earlier and later life; conversely, by means of improved calorie consumption, these variations are no more favorable and probably may direct to an augmented threat of MetS in a future part of life [57].

\section{Endothelium dysfunction}

A study by Hansson has shown that a diminution in nitric oxide, regarded as a vital monitor of endothelial function and a rise in ROS ends up in endothelial dysfunction. Thus, vasodilatation impairment decreased arterial acquiescence, and accelerated development of atherosclerosis can be prognostic factor to MetS [58]. An incapability of endothelium to provide its usual physiological and defensive mechanisms involves numerous factors such as oxidative stress, elevated blood glucose levels, complex glycation products, FFAs, cytokines, or adipokines [59].

\section{Role of cortisol}

Genetic predisposition in individuals, due to chronic hypercortisolism results in hypersecretion of cortisol, a hormone secreted during stress which perhaps accumulates fat deposition in the adipose tissue [60]. Cortisol increases the enzymatic activation concerned in the synthesis of fatty acid and thereby advancing the discharge of LDL and TG; provoking the liver for the gluconeogenesis; reduced uptake of amino acids and increased addition of oxygen to the lipids causes resistance to the insulin secretion [61]. Strong association was identified amidst the levels of cortisol, and the amount of characteristics of the MetS when studied on subjects; thus, hormonal alterations may lead to dyslipidemia, hypertension, and type 2 diabetes mellitus (T2DM) [62].

\section{CLINICAL MANIFESTATIONS OF METS}

MetS entails an augmented risk for mortality from CVD and also from increase in diabetes mellitus. The two components of MetS - Type 2 diabetes mellitus and coronary heart disease (CHD) - have acquired epidemic proportions globally. The escalating inhabitants of overweight and obese individuals constrain this rising threat. Even children with obesity are also at an increased risk of adolescent and adult obesity [63], which again enhances the threat of cardiovascular disease in later life. MetS is further related to many disorders polycystic ovary syndrome, obstructive sleep apnea, hypogonadism, and some forms of cancer [64].

Quality of life is much deteriorated in MetS patients, as there is a complete sluggish physical routine that affects the normal actions of patients [65]. Chronic MetS prevalence might show conclusive effects on physical comorbidities as observed in Fig. 5 .

\section{Cardiovascular disease}

The complication of MetS which includes CHD, myocardial infarction and also stroke be the principal reason behind the increased mortality rate in developed countries. A study by Mottillo et al. [67] exhibited that patients with MetS are more prone to develop T2DM and clinical CVD. Such study was also supported by another finding by Wilson et al. [68] that increased risk of CVD events exists in case of MetS. Furthermore, findings suggested that atherosclerosis and the threat of CVD rise with all the risk factors involved as MetS components $[66,69]$.

\section{Type II diabetes}

Type II diabetes is illustrated by decreased insulin production and insulin resistance. Most of the diabetic patients, who are obese, maybe perhaps reported with deficiency of insulin or its resistance. Chronic hyperglycemia and increased FFA levels resulting from lipolysis can inhibit the gene expression of insulin and as a result damage glucosedependent insulin production [70]. As a known fact that insulin stimulates uptake of glucose predominantly in fat cells, muscle build and in the hepatocytes. Insulin defiant would be an indicator for measuring people with MetS. Consequently, further insulin is necessary to activate the insulin-mediated glucose uptake by cells. Hyperglycemia, a causative factor for a diabetic which includes damage of retina, chronic loss of kidney function, dysfunction of peripheral nerves and angioplasty, linked with both decreased in the average lifespan of an individual, and considerable deterioration in the standard of health. MetS being a predecessor of Type 2 diabetes, the patients might have increased risk of CVD comorbidities [18,71].

Even after the progression of insulin resistance and metabolic anomalies, medical expression of the disease may not be present over some years. Before the development of T2DM disease, the advancement of macrovascular and microvascular disease is progressed [71]. The guidelines from NCEP ATP III illustrate that T2DM is an equivalent risk as CHD. Patients with diabetes and clinical atherosclerotic disease must take aggressive preventive measures [72].

\section{Steatohepatitis}

The most common causes of liver disease in adults are steatohepatitis (fatty liver). Fatty liver disease distinguished by liver injury and deposition of fat in the liver ( $<5 \%$ liver weight) [73]. Fatty liver further may lead to cirrhosis and liver failure. Damage of liver is also related with resistance to insulin, categorized by damaged ability of insulin to decrease the production of glucose from the liver. Consequently, resulting in mild decrease in sugar level and increased in insulin secretion, proceeding with hyperinsulinemia [74]. Thus, deposition of fat in liver is related with the mechanisms of the MetS. Rise in the occurrence of non-alcoholic fatty liver disease is accompanied with an epidemic of MetS. The relationship between MetS and steatohepatitis recommends that they may possibly share a mutual physiologic predecessor [75]. This association has led to the concern to observe its role in the development of CVD [76].

\section{Cancer}

The advanced risk in the colon or rectal cancer is allied with the magnitudes of adiposity and resistance to insulin in case MetS condition.

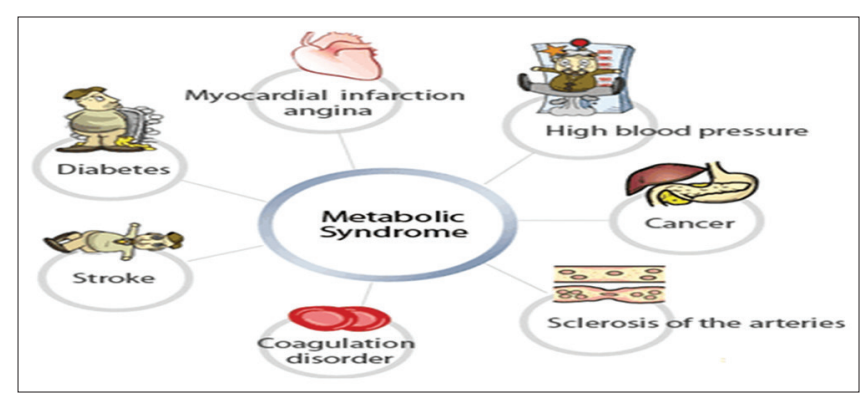

Fig. 5: Clinical implications of the metabolic syndrome 
Further a study by Harding et al. [65] found that those subjects with MetS components exhibit an augmented risk for colon or rectal cancer. Similar studies exhibited a possible connection that exists between breast cancer and MetS and also established that MetS amplifies the risk of breast cancer mortality [65,78]. There is a high susceptibility of MetS components to cause the evolution of tumor. Therefore, it is mandatory to differentiate the possible interlinks between these components and its risk [79].

\section{Other manifestations}

MetS is usually related with a disorder of the gastrointestinal tract, and also a study reported the fact that irritable bowel syndrome is present in most of MetS subjects. A study conducted by Chang et al., demonstrated that advanced pervasiveness of MetS was reported in adults with Helicobacter pylori infection [80].

Sleep apnea and polycystic ovarian syndrome (PCOS) are the other manifestations of MetS. MetS arise repeatedly in patients with obstructive sleep apnea due to obesity. Advanced incidence of cardiovascular morbidity and mortality is observed in patients with obstructive sleep apnea [81]. The incidence of MetS may probably explain the association between them [82]. Though PCOS, regarded as by ovulation, excess of androgen and glucose intolerance, the etiology of this syndrome remains unclear $[83,84]$. The pathogenic role in the progression of PCOS includes resistance to the insulin characterized by hyperinsulinemia [85]. Women with polycystic ovary syndrome are more prone to MetS; consequently, they are more susceptible to CVD. It is also described in a study where nearly half (46.4\%) of the women suffering with PCOS had MetS [83].

A true fact is observed in a study where Mets has been associated with beginning of chronic kidney disease [86]. Subsequent to percutaneous nephrolithotomy, a minimal invasive procedure to remove stones from the kidney, a study demonstrated that stone return rates and kidney damage were high as a consequence of MetS [87].

In recent times, it was observed that the group of mental disorders is in association with MetS prevalence [88]. A study reported that it is very common to be affected by bipolar disorder if the patients were already suffering from MetS. Furthermore, molecular level modifications observed in MetS including endothelial dysfunction can be bought in association with much type of central nervous system disorders such as anxiety, loss of memory, depression, and stroke [89].

Since cytokines and adipocytokines involvement and accountability are high in MetS, it could be easily associated with skin disease such as psoriasis [90].

\section{MANAGEMENT OF THE METS}

MetS can be easily managed by approaching through a dual point of view that unites non-pharmacological treatment and pharmacological considerations in an attempt to reduce many clinical conditions. To reduce the risk of many other diseases, prognosis and management become an essential part [91]. The implementation can be initiated with lifestyle changes, diet, weight loss, and exercise, which accounts for the non-pharmacological therapy. Nevertheless, if the MetS patients are not adequately responded with the preventive measures as mentioned use of drugs can be considered [92].

\section{Healthy diet}

Eating habits or the dietary pattern had become the major concern for the patients suffering from MetS. Proper care in healthy eating habits should produce a significant difference in MetS prevention. It is so common after the globalization, which processed foods are on garage trade extensively. MetS is more prone to, as there is excessive consumption of these calorie-rich foods. Dietary patterns that include elevated intakes of fresh fruits, greens, vegetables, fish, nuts, and cereals are proportionally associated with MetS mitigation. Research facts expose that the healthy diet can avert the MetS. Schools, universities, and social media should publicize healthy eating habits that include a sufficient consumption of good fats (monosaturated) and proteins among population worldwide. And also, the promotion of education about health on eating habits and their choices over food should be considered through pamphlets or community awareness. Every nation has their nutritional prototypes for the good choices of health and thereby attempting to avoid the MetS [93-95].

Low sodium ingestion provides a better effort to regularize the BP in patients suffering with MetS. Even in another study, it was reported that BP becomes very high in salt ingestions observed in case of MetS [96]. Similar study [97] evaluated during 1 year on male patients suffering from MetS, showed that the physical activity and healthy diet patterns had reduced the MetS incidence to almost 32.6\%. Less commonness of MetS is observed with populations sticking on to the Mediterranean diet. Moreover, such diet includes consumption of reduced carbohydrate and more monounsaturated fats that might prove to improvise MetS, especially by lowering the lipid levels, increasing the insulin action, and augmented performance of the liver. Moreover, to prevent MetS, all healthy diets should be promoted worldwide. And also, adaptation in an improvised food habits can advance the MetS occurrence at an early age and hence can revert its complication [93-95].

\section{Lifestyle modification}

Lifestyle adaptation method and some important views on health education should be shared by a team comprised all health-care professionals. Although there is a complete acceptance that these lifestyle behaviors such as weight loss and healthy dietary patterns are the first-line therapy to avoid the occurrence of MetS, the ultimate diet pattern and type of exercise remains vague [98-100].

Weight loss, insulin sensitivity, insulin action in muscles, elevation of HDL cholesterol levels, reduction in triglyceride levels, and decreased hypertension might result from an adequate amount of physical involvement through exercise. Through their actions on individual components such as obesity, waist circumference, and insulin resistance any form of physical exercise might defend against the progression of MetS $[101,102]$. Even studies have reported that there is a strong influence between the reduced levels of inflammatory mediators such as cytokines with increased physical activity [103]. In a 4 years followup study, as compared to the men whose physical activity is very less, men involving a reasonable or forceful physical activity were less prone to MetS [104]. Further, it is yet uncertain whether exercise only can decrease the risk of developing the MetS without the support of weight loss [100].

\section{Bariatric surgery}

Bariatric surgery is recommended especially for severe obesity and also for those subjects who have shown null response to the weight loss schemes. Due to the redistribution of fat, improvements in the lipid and biochemical report have been recognized [16]. A technique where a gastric bypass is made, and thus it has been found to improve other disorders such as diabetes, adiposity, elevated BP, steatohepatitis, CVD, dyslipidemia, and infertility [105]. Proper management is requiredas the long-term results remain uncertain and only very minimal safety is observed on geriatric patients.

\section{Pharmacotherapy}

Pharmacotherapy remains the nextoption tolifestyle modification. Longlasting use of several medications (polypharmacy) is preferred over specific drug prescribed as the present strategy of pharmacotherapy yet results in poor compliance [7]. Mostly the treatment involves lipid level management using statins, insulin expression or its sensitivity can be improvised by anti-diabetic drugs, hence reducing the risk of diabetes and deteriorating risk of clotting that inhibits the platelet aggregation. In addition, in an attempt to reduce the risk and development of MetS; nowadays, interest has also been turned toward the utilization of natural plant products their action on prolonged term remains unclear in regards to cardiovascular outcomes and compliance [8]. And also, a 
Table 1: Current definitions of MetS $[7,8]$

\begin{tabular}{|c|c|c|c|c|c|c|c|}
\hline Measures & WHO 1998 & EGIR 1999 & ICD-9 2000 & ATP III 2001 & ADA 2001 & IDF 2005 & AHA 2005 \\
\hline Insulin resistance & $\checkmark$ & $\checkmark$ & $\checkmark$ & - & $\checkmark$ & - & - \\
\hline Glucose intolerance & $\checkmark$ & $\checkmark$ & - & $\checkmark$ & $\checkmark$ & - & $\checkmark$ \\
\hline Diabetes & $\checkmark$ & - & - & $\checkmark$ & - & - & $\checkmark$ \\
\hline Hypertension & $\checkmark$ & $\checkmark$ & $\checkmark$ & $\checkmark$ & $\checkmark$ & $\checkmark$ & $\checkmark$ \\
\hline High TG & $\checkmark$ & $\checkmark$ & $\checkmark$ & $\checkmark$ & $\checkmark$ & $\checkmark$ & $\checkmark$ \\
\hline Low HDL & $\checkmark$ & $\checkmark$ & $\checkmark$ & $\checkmark$ & $\checkmark$ & $\checkmark$ & $\checkmark$ \\
\hline Abdominal adiposity & $\checkmark$ & $\checkmark$ & $\checkmark$ & $\checkmark$ & $\checkmark$ & - & $\checkmark$ \\
\hline
\end{tabular}

MetS: Metabolic syndrome, WHO: World Health Organization, EGIR: European Group for the study of Insulin Resistance, ICD-9: International Classification of

Diseases ( $9^{\text {th }}$ revision), ATP: Adult treatment panel III, ADA: American Diabetes Association, IDF: International Diabetes Federation, AHA: American Heart Association,

TG: Triglycerides, HDL: High-density lipoprotein

Table 2: Multifaceted approach to MetS [109]

\begin{tabular}{ll}
\hline Category & Approaches \\
\hline A: Aspirin & High risk: Aspirin definitely beneficial \\
B: Control in BP & Commence treatment if only BP rises above $140 / 90 \mathrm{mmHg}$ \\
& Start treatment if subjects with diabetes have BP more than $130 / 80 \mathrm{mmHg}$. \\
& First line drugs such as angiotensin-converting enzyme inhibitors or angiotensin receptor blockers could be \\
& preferred \\
& Statins to be preferred to lower LDL values and to increase HDL \\
C: Cholesterol & If statins course is complete commence with niacin and fibrates \\
& If the patients have more triglycerides and reduced HDL prefer fibrates \\
& Consider lifestyle adaptation \\
D: Diabetes control & Initiate weight loss strategy up to 6 months duration \\
& Intake of adequate amount of fruits, vegetables, greens, and grains \\
& Moderate intake of meat and milk products \\
& Second line drugs: Metformin is preferred to reduce the risk of diabetes \\
& Third line drugs: Advantage of alpha-glucosidase inhibitors and thiazolidinediones is seen in smaller studies \\
& Minimum to modest physical activity daily for 30 min \\
E: Exercise and physical activity & Preferably walking \\
\hline BP: Blood pressure, MetS: Metabolic syndrome, LDL: Low-density lipoprotein, HDL: High-density lipoprotein
\end{tabular}

multifaceted approach to MetS can be considered as in Table 2.

Management of MetS through drugs is suggested over lifestyle measures in patients with cardiovascular comorbidities to reach the targeted goals for reducing the lipoprotein levels and to regulate hypertension [25]. Drug classification for the treatment of MetS comprises of statins, fibrates, and angiotensin-converting enzyme inhibitors or angiotensin receptor blockers [24]. The underlying conditions that advance the development of MetS and diabetes mellitus are obesity, physical inactivity, and diet; therefore, lifestyle modifications are the first step for the prevention of it. Hence, to avert and diminish the advancement of MetS as well, the cardiovascular mortalities earlier prognosis and management remains crucial [53].

\section{CONCLUSION}

MetS has an augmented risk of diabetes mellitus and cardiovascular disorder. The incidence of numerous causative factors demands multifactorial management that encompasses glycemic control, lipidlowering therapy, BP regulation, and antiplatelet treatment. Nonpharmacological therapy such as lifestyle interventions being the preliminary preference that usually determines a strategy that works with particular dietary patterns and regular physical activity. Healthy diet patterns that include elevated intakes of fresh fruits, greens, vegetables, fish, nuts, and cereals are proportionally associated with MetS mitigation. Although MetS prevalence remains globally, it is developed through numerous factors such as food choices, exercise, innate genetic influence, status, gender, living era, nd educational occupation. To elucidate the origin, a mandatory step must be taken to focus on these components. Mostly, the quality of life of these MetS patients may be perhaps affected due to their sedentary behavior. Management of MetS includes treatment such as scheduled exercise, list of pharmacologically classified drugs or even the interventional procedures. This review presently demonstrated that increased physical activity has distinguished importance in MetS avoidance and revival; mainly food choices with regular diet are proportionately linked with MetS improvement. Further research will be explored to encourage the clinical diagnosis and also must depict the true impact of effective management of all elements pertaining to this syndrome.

\section{ACKNOWLEDGMENTS}

The authors wish to acknowledge the management of the School of Pharmaceutical Sciences, Vels Institute of Science Technology and Advanced Studies (VISTAS), Chennai, India.

\section{CONFLICTS OF INTEREST}

The authors certify that they have NO affiliations with or involvement in any organization or entity with any financial interest or non-financial interest in the subject matter or materials discussed in this manuscript.

\section{REFERENCES}

1. Alberti KG, Zimmet P, Shaw J; IDF Epidemiology Task Force Consensus Group. The metabolic syndrome - A new worldwide definition. Lancet 2005;366:1059-62.

2. Kaur J. Assessment and screening of the risk factors in metabolic syndrome. Med Sci 2014;2:140-52.

3. Grundy SM. Point: The metabolic syndrome still lives. Clin Chem 2005;51:1352-4

4. Kahn R, Buse J, Ferrannini E, Stern M. The metabolic syndrome: Time for a critical appraisal. Joint statement from the American diabetes association and the European association for the study of diabetes. Diabetes Care 2005;28:2289-304.

5. Dabou S, Telefo PB, Sama LF. Evaluation of dietary habits and lifestyle on the prevalence of metabolic syndrome and obesity in undergraduate university students in Cameroon: A cross sectional study. J Metab Synd 2018;7:1.

6. Alberti KG, Eckel RH, Grundy SM, Zimmet PZ, Cleeman JI, 
Donato KA, et al. Harmonizing the metabolic syndrome: A joint interim statement of the international diabetes federation task force on epidemiology and prevention; national heart, lung, and blood institute; American heart association; world heart federation; international atherosclerosis society; and international association for the study of obesity. Circulation 2009;120:1640-5.

7. National Cholesterol Education Program (NCEP) Expert Panel on Detection. Evaluation, and treatment of high blood cholesterol in adults (Adult Treatment Panel III). Circulation 2002;106:3143-421.

8. Rochlani Y, Pothineni NV, Kovelamudi S, Mehta JL. Metabolic syndrome: Pathophysiology, management, and modulation by natural compounds. Ther Adv Cardiovasc Dis 2017;11:215-25.

9. World Health Organization. Definition, Diagnosis and Classification of Diabetes Mellitus and its Complications: Report of a WHO Consultation. Part 1: Diagnosis and Classification of Diabetes Mellitus. Geneva. World Health Organization; 1999. WHO/NCD/NCS/99.2.

10. Balkau B, Charles MA. Comment on the provisional report from the WHO consultation. European group for the study of insulin resistance (EGIR) Diabet Med 1999;16:442-3.

11. Executive Summary of the Third Report of the National Cholesterol Education Program (NCEP) Expert Panel on Detection. Evaluation, and treatment of high blood cholesterol in adults (Adult Treatment Panel III). JAMA 2001;285:2486-97.

12. Zimmet PZ, Alberti KG, Shaw JE. Mainstreaming the metabolic syndrome: A definitive definition. Med J Aust 2005;183:175-6.

13. Shaw JE, Chisholm DJ. 1: Epidemiology and prevention of type 2 diabetes and the metabolic syndrome. Med J Aust 2003;179:379-83.

14. Avogaro P, Crepaldi G. Essential hyperlipidemia, obesity and diabetes. Diabetologia 2003;1:137.

15. Reaven GM. Role of insulin resistance in human disease. Diabetes 1988;37:1595-607.

16. Eckel RH, Grundy SM, Zimmet PZ. The metabolic syndrome. Lancet 2005;365:1415-28.

17. Hu G, Qiao Q, Tuomilehto J, Balkau B, Borch-Johnsen K, Pyorala K, et al. Prevalence of the metabolic syndrome and its relation to allcause and cardiovascular mortality in nondiabetic European men and women. Arch Intern Med 2004;164:1066-76.

18. Hu G, Lindström J, Jousilahti P, Peltonen M, Sjöberg L, Kaaja R, et al. The increasing prevalence of metabolic syndrome among Finnish men and women over a decade. J Clin Endocrinol Metab 2008;93:832-6.

19. Ilanne-Parikka P, Eriksson JG, Lindström J, Hämäläinen H, KeinänenKiukaanniemi S, Laakso M, et al. Prevalence of the metabolic syndrome and its components: Findings from a Finnish general population sample and the diabetes prevention study cohort. Diabetes Care 2004;27:2135-40.

20. Ford ES, Giles WH, Dietz WH. Prevalence of the metabolic syndrome among US adults: Findings from the third national health and nutrition examination survey. JAMA 2002;287:356-9.

21. Cortez-Dias N, Martins S, Belo A, Fiuza M, Investigadores do estudo VALSIM. Comparison of definitions of metabolic syndrome in relation to risk for coronary artery disease and stroke. Rev Port Cardiol 2011;30:139-69.

22. Lechleitner M. Obesity and the metabolic syndrome in the elderly - a mini-review. Gerontology 2008;54:253-9.

23. Cornier MA, Dabelea D, Hernandez TL, Lindstrom RC, Steig AJ, Stob NR, et al. The metabolic syndrome. Endocr Rev 2008;29:777-822.

24. Desroches S, Lamarche B. The evolving definitions and increasing prevalence of the metabolic syndrome. Appl Physiol Nutr Metab 2007;32:23-32.

25. Park YW, Zhu S, Palaniappan L, Heshka S, Carnethon MR, Heymsfield SB, et al. The metabolic syndrome: Prevalence and associated risk factor findings in the US population from the third national health and nutrition examination survey, 1988-1994. Arch Intern Med 2003;163:427-36.

26. Matsuzawa Y, Funahashi T, Nakamura T. The concept of metabolic syndrome: Contribution of visceral fat accumulation and its molecular mechanism. J Atheroscler Thromb 2011;18:629-39.

27. Kohler HP, Grant PJ. Plasminogen-activator inhibitor type 1 and coronary artery disease. N Engl J Med 2000;342:1792-801.

28. Boden G, Shulman GI. Free fatty acids in obesity and type 2 diabetes: Defining their role in the development of insulin resistance and betacell dysfunction. Eur J Clin Invest 2002;32 Suppl 3:14-23.

29. Bremer AA, Mietus-Snyder M, Lustig RH. Toward a unifying hypothesis of metabolic syndrome. Pediatrics 2012;129:557-70

30. Vague IJ, Alessi MC, Mavri A, Morangi PE. Plasminogen activator inhibitor-1, inflammation, obesity, insulin resistance and vascular risk. J Thromb Haemost 2003;1:1575-9.
31. de Ferranti S, Mozaffarian D. The perfect storm: Obesity, adipocyte dysfunction, and metabolic consequences. Clin Chem 2008;54:945-55.

32. Lewis GF, Steiner G. Acute effects of insulin in the control of VLDL production in humans. Implications for the insulin-resistant state. Diabetes Care 1996;19:390-3.

33. Kern PA, Saghizadeh M, Ong JM, Bosch RJ, Deem R, Simsolo RB, et al. The expression of tumor necrosis factor in human adipose tissue. Regulation by obesity, weight loss, and relationship to lipoprotein lipase. J Clin Invest 1995;95:2111-9.

34. Weiss R, Caprio S. The metabolic consequences of childhood obesity. Best Pract Res Clin Endocrinol Metab 2005;19:405-19.

35. Lemieux I, Pascot A, Couillard C, Lamarche B, Tchernof A, Alméras N, et al. Hypertriglyceridemic waist: A marker of the atherogenic metabolic triad (hyperinsulinemia; hyperapolipoprotein B; small, dense LDL) in men? Circulation 2000;102:179-84

36. Flegal KM, Carroll MD, Ogden CL Johnson CL. Prevalence and trends in obesity among US adults, 1999-2000. JAMA 2002;288:1723-7.

37. Festa A, D'Agostino R Jr., Williams K, Karter AJ, Davis EJ, Tracy RP, et.al. The relation of body fat mass and distribution to markers of chronic inflammation. Int J Obes 2001;25:1407-15.

38. Hunter I, Soler A, Joseph G, Hutcheson B, Bradford C, Zhang FF, et al. Cardiovascular function in male and female JCR: LA-cp rats: Effect of high-fat/high-sucrose diet. Am J Physiol Heart Circ Physiol 2017;312:H742-H751

39. Koster A, Stenholm S, Alley DE, Kim LJ, Simonsick EM, Kanaya AM, et al. Body fat distribution and inflammation among obese older adults with and without metabolic syndrome. Obesity (Silver Spring) 2010;18:2354-61.

40. Gill H, Mugo M, Whaley-Connell A, Stump C, Sowers JR. The key role of insulin resistance in the cardiometabolic syndrome. Am J Med Sci 2005;330:290-4

41. Grundy SM, Hansen B, Smith SC, Cleeman JI, Kahn RA; Conference Participants. Clinical management of metabolic syndrome: Report of the American heart association/national heart, lung, and blood institute/ American diabetes association conference on scientific issues related to management. Circulation 2004;109:551-6.

42. Vanecková I, Maletínská L, Behuliak M, Nagelova V, Zicha J, Kunes J. Obesity-related hypertension: Possible pathophysiological mechanisms. J Endocrinol 2014;223:R63-78.

43. Mehta PK, Griendling KK. Angiotensin II cell signaling: Physiological and pathological effects in the cardiovascular system. Am J Physiol Cell Physiol 2007;292:C82-97.

44. Gonal F, Deshmukh A, Shah S, Mehta JL. Triad of metabolic syndrome, chronic kidney disease, and coronary heart disease with a focus on microalbuminuria: Death by overeating. J Am Coll Cardiol 2011;57:2303-8

45. Dai Y, Mercanti F, Dai D, Wang X, Ding Z, Pothineni NV, et al. LOX-1, a bridge between GLP-1R and mitochondrial ROS generation in human vascular smooth muscle cells. Biochem Biophys Res Commun 2013;437:62-6.

46. Ferrannini E, Natali A. Essential hypertension, metabolic disorders, and insulin resistance. Am Heart J 1991;121:1274-82.

47. Brunzell JD, Ayyobi AF. Dyslipidemia in the metabolic syndrome and type 2 diabetes mellitus. Am J Med 2003;115 Suppl 8A:24S-28S.

48. Pant S, Deshmukh A, Gurumurthy GS, Pothineni NV, Watts TE, Romeo $\mathrm{F}$, et al. Inflammation and atherosclerosis - Revisited. J Cardiovasc Pharm Ther 2014;19:170-8.

49. Hotamisligil GS, Murray DL, Choy LN, Spiegelman BM. Tumor necrosis factor alpha inhibits signalling from the insulin receptor. Proc Natl Acad Sci USA 1994;91:4854-8

50. Tsigos C, Kyrou I, Chala E, Tsapogas, Stavridis JC, Raptis SA, et al. Circulating tumor necrosis factor alpha concentrations are higher in abdominal versus peripheral obesity. Metabolism 1999;48:1332-5.

51. Fried SK, Bunkin DA, Greenberg AS. Omental and subcutaneous adipose tissues of obese subjects release interleukin-6: Depot difference and regulation by glucocorticoid. J Clin Endocrinol Metab 1998;83:847-50

52. Bastard JP, Jardel C, Bruckert E, Blondy P, Capeau J, Laville M, et al. Elevated levels of interleukin 6 are reduced in serum and subcutaneous adipose tissue of obese women after weight loss. J Clin Endocrinol Metab 2000;85:3338-42.

53. Wisse BE. The inflammatory syndrome: The role of adipose tissue cytokines in metabolic disorders linked to obesity. J Am Soc Nephrol 2004; $15: 2792-800$

54. Lewisand GF, Steiner G. Acute effects of insulin in the control of VLDL production in humans: implications for the insulin resistant state. Diabetes Care 1996;19:390-3. 
55. Ginsberg HN, Zhang YL, Hernandez-Ono A. Regulation of plasma triglycerides in insulin resistance and diabetes. Arch Med Res 2005;36:232-40.

56. Ordovas JM. Genetic links between diabetes mellitus and coronary atherosclerosis. Curr Atheroscler Rep 2007;9:204-10.

57. Poulsen P, Levin K, Petersen I, Christensen K, Nielsen HB, Vaag A. Heritability of insulin secretion, peripheral and hepatic insulin action, and intracellular glucose partitioning in young and old Danish twins. Diabetes 2005;54:275-83.

58. Hansson GK. Mechanisms of disease: Inflammation, atherosclerosis, and coronary artery disease. N Engl J Med 2005;352:1685-95.

59. Kraemer-Aguiar LG, Laflor CM, Bouskela E. Skin microcirculatory dysfunction is already present in normoglycemic subjects with metabolic syndrome. Metabolism 2008;57:1740-6.

60. Charmandari E, Tsigos C, Chrousos G. Endocrinology of the stress response. Annu Rev Physiol 2005;67:259-84.

61. Andrew R, Gale CR, Walker BR, Seckl JR, Martyn CN. Glucocorticoid metabolism and the metabolic syndrome: Associations in an elderly cohort. Exp Clin Endocrinol Diabetes 2002;110:284-90.

62. Chrousos GP. Stress and disorders of the stress system. Nat Rev Endocrinol 2009;5:374-81.

63. Whitaker RC, Wright JA, Pepe MS, Seidel KD, Dietz WH. Predicting obesity in young adulthood from childhood and parental obesity. N Engl J Med 1997;337:869-73.

64. Barquero SC, Leon AM, Sadurni M, Estruch R, Casas R. Dietary strategies for metabolic syndrome: A review. J Obes Ther 2017;1:2

65. Harding J, Sooriyakumaran M, Anstey KJ, Adams R, Balkau B, Briffa T, et al. The metabolic syndrome and cancer: Is the metabolic syndrome useful for predicting cancer risk above and beyond its individual components? Diabetes Metab 2015;41:463-9.

66. Mottillo S, Filion KB, Genest J, Joseph L, Pilote L, Poirier P, et al. The metabolic syndrome and cardiovascular risk a systematic review and meta-analysis. J Am Coll Cardiol 2010;56:1113-32.

67. Wilson PW, D'Agostino RB, Parise H, Sullivan L, Meigs JB. Metabolic syndrome as a precursor of cardiovascular disease and type 2 diabetes mellitus. Circulation 2005;112:3066-72.

68. Yusuf S, Hawken S, Ounpuu S, Bautista L, Franzosi MG, Commerford $\mathrm{P}$, et al. Obesity and the risk of myocardial infarction in 27,000 participants from 52 countries: A case-control study. Lancet 2005;366:1640-9

69. Nissen SE, Nicholls SJ, Sipahi I, Libby P, Raichlen JS, Ballantyne CM, et al. Effect of very high-intensity statin therapy on regression of coronary atherosclerosis: The asteroid trial. JAMA 2006;295:1556-65.

70. Haffner SM, Stern MP, Hazuda HP, Mitchell BD, Patterson JK. Cardiovascular risk factors in confirmed prediabetic individuals. Does the clock for coronary heart disease start ticking before the onset of clinical diabetes? JAMA 1990;263:2893-8.

71. Pyörälä M, Miettinen H, Halonen P, Laakso M, Pyörälä K. Insulin resistance syndrome predicts the risk of coronary heart disease and stroke in healthy middle-aged men: The 22-year follow-up results of the helsinki policemen study. Arterioscler Thromb Vasc Biol 2000;20:538-44

72. Reaven GM, Lithell H, Landsberg L. Hypertension and associated metabolic abnormalities - The role of insulin resistance and the sympatho adrenal system. N Engl J Med 1996;334:374-81.

73. Kotronen A, Westerbacka J, Bergholm R, Pietiläinen KH, YkiJärvinen H. Liver fat in the metabolic syndrome. J Clin Endocrinol Metab 2007:92:3490-7.

74. Clark JM. The epidemiology of non-alcoholic fatty liver disease in adults. J Clin Gastroenterol 2006;40:S5-10.

75. Kotronen A, Yki-Järvinen H. Fatty liver: A novel component of the metabolic syndrome. Arterioscler Thromb Vascu Biol 2008;28:27-38.

76. Targher G, Day CP, Bonora E. Risk of cardiovascular disease in patients with nonalcoholic fatty liver disease. N Engl J Med 2010;363:1341-50.

77. Bjørge T, Lukanova A, Jonsson H, Tretli S, Ulmer H, Manjer J, et al. Metabolic syndrome and breast cancer in the me-can (metabolic syndrome and cancer) project. Cancer Epidemiol Biomarkers Prev 2010;19:1737-45.

78. Cowey S, Hardy RW. The metabolic syndrome: A high-risk state for cancer? Am J Pathol 2006;169:1505-22.

79. Chang YC, Huang CY, Hwang LC, Chang CC. The association between helicobacter pylori infection and metabolic syndrome in a Taiwanese adult population. J Metab Synd 2017;6:4.
80. Hamilton GS, Solin P, Naughton MT. Obstructive sleep apnoea and cardiovascular disease. Intern Med J 2004;34:420-6.

81. Vgontzas AN, Bixler EO, Chrousos GP. Sleep apnea is a manifestation of the metabolic syndrome. Sleep Med Rev 2005;9:211-24.

82. Glueck CJ, Papanna R, Wang P, Goldenberg N, Sieve-Smith L. Incidence and treatment of metabolic syndrome in newly referred women with confirmed polycystic ovarian syndrome. Metabol Clin Exp 2003;52:908-15.

83. Legro RS. A 27-year-old woman with a diagnosis of polycystic ovary syndrome. JAMA 2007;297:509-19.

84. Apridonidze T, Essah PA, Iuorno MJ, Nestler JE. Prevalence and characteristics of the metabolic syndrome in women with polycystic ovary syndrome. J Clin Endocrinol Metabol 2005;90:1929-35.

85. Watanabe H, Obata H, Watanabe T, Sasaki S, Nagai K, Aizawa Y, et al. Metabolic syndrome and risk of development of chronic kidney disease: The niigata preventive medicine study. Diabetes Metab Res Rev 2010;26:26-32.

86. Akman T, Binbay M, Erbin A, Tepeler A, Sari E, Kucuktopcu O, et al. The impact of metabolic syndrome on long-term outcomes of percutaneous nephrolithotomy (PCNL). BJU Int 2012;110:E1079-83.

87. Babić D, Maslov B, Martinac M, Nikolić K, Uzun S, Kozumplik O. Bipolar disorder and metabolic syndrome: Comorbidity or side effects of treatment of bipolar disorder. Psychiatr Danub 2010;22:75-8.

88. Farooqui AA, Farooqui T, Panza F, Frisardi V. Metabolic syndrome as a risk factor for neurological disorders. Cell Mol Life Sci 2012;69:741-62.

89. Takahashi H, Iizuka H. Psoriasis and metabolic syndrome. J Dermatol 2012;39:212-8.

90. Wong ND. Intensified screening and treatment of the metabolic syndrome for cardio vascular risk reduction. Prev Cardiol 2005;8:47-54.

91. Deen D. Metabolic syndrome: Time for action. Am Fam Physician 2004;69:2875-82

92. Youngwanichsetha S. Healthy eating for prevention of the metabolic syndrome. J Nutr Food Sci 2018;8:3

93. Diego J, Camacho H, Hernández-Camachob M. Clinical update on metabolic syndrome. Rev Esp Nutr Hum Diet 2017;21:384-92.

94. Jarbøl DE, Larsen PV, Gyrd-Hansen D, Søndergaard J, Brandt C, Leppin A, et al. Determinants of preferences for lifestyle changes versus medication and beliefs in ability to maintain lifestyle changes. A population-based survey. Prev Med Rep 2017;6:66-73.

95. Hoffmann IS, Cubeddu LX. Increased blood pressure reactivity to dietary salt in patients with the metabolic syndrome. J Hum Hypertens 2007;21:438-44.

96. Anderssen SA, Carroll S, Urdal P, Holme I. Combined diet and exercise intervention reverses the metabolic syndrome in middle-aged males: Results from the oslo diet and exercise study. Scand J Med Sci Sports 2007; 17:687-95.

97. Esposito K, Giugliano D. Mediterranean diet and the metabolic syndrome: The end of the beginning. Metab Syndr Relat Disord 2010;8:197-200.

98. Blair SN, Cheng Y, Holder JS. Is physical activity or physical fitness more important in defining health benefits? Med Sci Sports Exerc 2001;33:S379-99.

99. Magkos F, Yannakoulia M, Chan JL, Mantzoros CS. Management of the metabolic syndrome and Type 2 diabetes through lifestyle modification. Annu Rev Nutr 2009;29:223-56.

100. Papakonstantinou E, Lambadiari V, Dimitriadis G, Zampelas A. Metabolic syndrome and cardiometabolic risk factors. Curr Vasc Pharmacol 2013;11:858-79.

101. Lakka TA, Laaksonen DE, Lakka HM, Männikkö N, Niskanen LK, Rauramaa R, et al. Sedentary lifestyle, poor cardiorespiratory fitness, and the metabolic syndrome. Med Sci Sports Exerc 2003;35:1279-86.

102. Roberts CK., Won D., Pruthi S., Lin SS., Barnard, R. J. Effect of a diet and exercise intervention on oxidative stress, inflammation and monocyte adhesion in diabetic men. Diabetes Research and Clin Pract 2008; 73:249-59

103. Laaksonen DE, Lakka HM, Salonen JT, Niskanen LK, Raurama R, Lakka TA. Low levels of leisure-time physical activity and cardiorespiratory fitness predict development of the metabolic syndrome. Diabetes Care 2002;25:1612-1618.

104. Sjöström L, Lindroos AK, Peltonen M, Torgerson J, Bouchard C, Carlsson B, et al. Lifestyle, diabetes, and cardiovascular risk factors 10 years after bariatric surgery. N Engl J Med 2004;351:2683-93.

105. Kaur J. A comprehensive review on metabolic syndrome. Cardiol Res Pract 2014;2014:943162. 